\title{
UMA CRENÇA NÃO ESTÁ FUNDAMENTADA SE SUBSISTEM OBJEÇÕES SEM RESPOSTA - OU A OBVIEDADE NECESSÁRIA DO ART. 489, § 1., IV, DO CPC ${ }^{1}$
}

\section{A BELIEF IS NOT FOUNDED IF REMAINS UNANSWERED ANY OBJECTION TO IT}

- OR THE NECESSARY OBVIOUSNESS OF ART. 489, § 1, IV, OF BRAZILIAN CIVIL

\section{PROCEDURAL CODE}

Hugo de Brito Machado Segundo

Mestre e Doutor em Direito. Professor Associado da Faculdade de Direito da Universidade Federal do Ceará, de cujo Programa de Pós-Graduação (Mestrado/Doutorado) foi Coordenador (2012/2016) e do Centro Universitário Chrisuts (Unichristus). Membro do ICET - Instituto Cearense de Estudos Tributários, do IBDT - Instituto Brasileiro de Direito Tributário e da WCSA World Complexity Science Academy. Visiting Scholar da Wirtschaftsuniversität, Viena, Áustria. Advogado em Fortaleza/CE. Fortaleza/CE. E-mail: hugo.segundo@ufc.br

RESUMO: Em um cenário de crescente protagonismo do Poder Judiciário, adquirem ainda maior relevo mecanismos destinados a controlar racionalmente a atividade de seus membros, dentre os quais se destaca o dever de fundamentar decisões judiciais. Neste artigo, parte-se da hipótese de que é indispensável, para que uma decisão seja considerada fundamentada, que nela se refutem todas as objeções que lhe tenham sido levantadas, e que sejam, em tese, capazes de infirmá-la. A partir de pesquisa bibliográfica, seguindo metodologia hipotético dedutiva e falibilista, verificar-se-á se tal conjectura decorre, e é compatível, não só com princípios constitucionais processuais, a exemplo do direito de petição, da ampla defesa e do contraditório, mas com a própria compreensão da Epistemologia a respeito da fundamentação do conhecimento e das crenças em geral. Verificar-se-á, com isso, se o art. 489, § 1. o , IV, do CPC/2015, caso se conclua que enuncia o óbvio, é aplicável a outros subsistemas processuais,

\footnotetext{
${ }^{1}$ Artigo recebido em 25/05/2020 e aprovado em 23/12/2020.
} 
a exemplo do administrativo, do trabalhista ou do penal, independentemente do que disponha a legislação infraconstitucional específica.

PALAVRAS-CHAVE: Crenças. Fundamentação. Dever de motivação.

\begin{abstract}
Due to a increasing protagonism by the Judiciary, legal mechanisms to rationally control the activity of its members acquire even greater importance. One of these legal mechanisms is the duty to make explicit the base of their decisions. In this paper, we start from the hypothesis that it is essential, for a decision to be considered based or grounded, that all objections that have been raised to it are refuted. Based on bibliographic research, following hypothetical deductive and fallibilism methodology, it will be verified whether this conjecture arises, and is compatible, not only with constitutional procedural principles, such as the right to petition and the due process of law, but with the way Epistemology understand the foundation of knowledge and beliefs in general. With this, it will be verified whether art. 489, § 1, IV, of Brazilian Civil Procedural Code, since prescribes an obviousness, is applicable to other procedural subsystems, such as administrative procedural law, and labor or criminal procedural law, regardless of the specific infra-constitutional legislation.
\end{abstract}

KEYWORDS: Beliefs. Duty of motivation. Legal reasoning.

\title{
Introdução
}

Nos últimos anos, assumiu maior importância, em estudos jurídicos, notadamente de Direito Processual Civil, o exame da fundamentação das decisões judiciais. É possível, aliás, observar uma sequência que talvez explique esse incremento na atenção dada ao tema. Primeiro, ao longo dos anos 90 do Século XX, por influência da Constituição promulgada em 1988, a literatura jurídica nacional, e a produção acadêmica verificada nos Programas de PósGraduação em Direito, ocupou-se bastante da descoberta de novos direitos fundamentais, e de princípios constitucionais, os quais, se não fossem efetivados pelo Executivo ou pelo Legislativo, poderiam dar margem à judicialização do tema, por terem status constitucional. Em seguida, exame da literatura, e das pesquisas produzidas nos Programas de Pós, mostra o surgimento de um novo tema, que passou a assumir posição de destaque: crítica ao Poder 
Judiciário e ao que seria uma indevida judicialização da política, um nocivo ativismo judicial. Essa crítica, porém, é insuficiente se não se apontam critérios ou instrumentos para que se possa tentar remediar o problema. Do contrário, passa-se a impressão de que, para quem as faz, incorretas - fruto de indevido "ativismo" - seriam todas aquelas decisões com as quais simplesmente não se concorda. Para que a crítica tenha substância, exigem-se motivos.

É nesse cenário que, já na segunda década do Século XXI, assume, na pesquisa jurídica nacional, posição de destaque o debate centrado na questão da fundamentação das decisões judiciais. Debate que não é, ou não deveria ser, muito diverso daquele estabelecido no que tange às crenças em geral, inclusive das que são adotadas por cientistas na construção de teorias. Nesse contexto, e naturalmente sem pretender examinar todos os aspectos da questão, o presente artigo parte da premissa de que não se podem considerar fundamentadas decisões que deixem sem resposta objeções que tenham sido levantadas e que sejam, em tese, capazes de infirmá-las. É o que consta, didaticamente, do art. 489, § 1. ${ }^{\circ}$, do CPC $/ 2015^{2}$.

Pode parecer pouco relevante estudar o assunto - a necessidade de se refutarem todas as objeções levantadas contra uma conclusão, para que ela seja considerada suficientemente fundamentada - diante da existência de norma expressa a determiná-lo, mas não é. Primeiro, veja-se que, antes de publicado o Código de Processo Civil de 2015, o entendimento jurisprudencial que prevalecia era precisamente o oposto, vale dizer, de que o magistrado não seria obrigado a responder todos os argumentos suscitados pelas partes. Em segundo lugar, mesmo depois de publicado o Código de Processo Civil ora em vigor, não faltaram vozes a afirmar a "inaplicabilidade" de tal artigo. Foi o caso, por exemplo, de algumas decisões na órbita da Justiça do Trabalho.

O objetivo deste artigo, nesse contexto, é o de demonstrar, a partir de pesquisa bibliográfica no campo da epistemologia e da argumentação, que é indispensável, para que uma decisão seja considerada fundamentada, que nela se refutem todas as objeções que lhe tenham sido levantadas, e que sejam, em tese, capazes de infirmá-la. Concluir-se-á, em suma, que não se trata de uma imposição apenas do art. $489, \S 1 .^{\circ}, \mathrm{IV}$, do $\mathrm{CPC} / 2015$, que a rigor enuncia o óbvio, mas da própria maneira como se fundamentam as crenças em geral, das quais aquelas que amparam uma decisão judicial são uma espécie.

\footnotetext{
2 “Art. 489. (...) $\S 1^{\circ}$ Não se considera fundamentada qualquer decisão judicial, seja ela interlocutória, sentença ou acórdão, que: (...) IV - não enfrentar todos os argumentos deduzidos no processo capazes de, em tese, infirmar a conclusão adotada pelo julgador; (...)"
} 


\section{A fundamentação das crenças em geral, e das que amparam decisões judiciais em particular}

Conhecimento é palavra que, como raciocínio, pensamento e interpretação, sofre da dubiedade "processo/resultado", por designar, dentre outras coisas, uma série de atos destinada a um resultado final e, também, alternativamente, esse resultado. Diz-se, assim, que o conhecimento é uma "relação" entre um sujeito que conhece e um objeto que é conhecido, definição geralmente presente em livros de Epistemologia. O sentido, aí, é de resultado. Mas utiliza-se também a palavra para a aludir ao resultado desse processo, vale dizer, a imagem desse objeto, formada pelo sujeito e em seguida objetivada em linguagem e compartilhada com os demais membros da comunidade. É o caso de quando se diz, v.g., que "o conhecimento humano a respeito da Física indica não ser possível ultrapassar a velocidade da luz."

Não é o caso, aqui, de aprofundar discussões de Teoria do Conhecimento sobre a natureza do conhecimento, e sobre as concepções de verdade. Para que se possa examinar o sentido e o alcance do dever de fundamentar decisões, sejam elas administrativas ou judiciais, é suficiente saber que o conhecimento, nesse segundo sentido, de resultado do processo, é composto de crenças fundamentadas.

Em tese, três graus de justificação são possíveis ${ }^{3}$, na fundamentação de uma crença ${ }^{4}$.

Uma crença, ou uma alegação feita a alguém (como consequência dessa crença), pode ter uma justificação qualquer. Aquele que formula a alegação, e a quem se pedem justificativas, utiliza qualquer coisa para tanto, mesmo que não faça sentido algum:

- Nosso cão está com fome.

- Sério? Como sabe?

- Porque Napoleão perdeu a batalha de Waterloo...

A justificativa apresentada, Napoleão Bonaparte ter perdido a batalha de Waterloo em 1815, evidentemente não guarda qualquer relação de causa e efeito com o fato de um animal canino estar com fome mais de dois séculos depois. Trata-se de justificativa inaceitável, mas

\footnotetext{
${ }^{3}$ Use-se a palavra "possível”, aqui, no sentido de factualmente verificável, ou seja, algo que de fato pode ocorrer, sem juízos de valor sobre se isso seria bom, admissível, permissível etc. Em alemão, essa "possibilidade" seria traduzível como kennen (Não posso nadar porque não sei nadar, se cair na piscina me afogo), e não como dürfen (Sou exímio nadador, mas não posso nadar porque é proibido e se o fizer serei multado).

${ }^{4}$ MARCONI, Diego. Per la verità. Relativismo e filosofia. Torino: Einaudi, 2007, p. 6-14.
} 
que factualmente foi apresentada como tal. Tem-se, aqui, um primeiro tipo, grau ou nível de justificação, que Diego Marconi chama de "J1".

Mas pode ser que a justificativa seja não apenas apresentada como razão para a veracidade da crença de cuja veracidade se cogita. Pode ser que ela não atenda apenas os requisitos mínimos para ser considerada J1, e que são insatisfatórios, é claro. Pode ser que a justificativa seja também convincente, fazendo com que as pessoas a quem é dirigida passem a crer na veracidade daquela alegação assim justificada. Seguindo na terminologia de Marconi, a justificativa, chegando a esse segundo nível, chama-se "J2". Retornando ao exemplo, pode-se dizer:

- Nosso cão está com fome.

- Sério? Como sabe?

- Porque já é tarde e ele ainda não comeu hoje.

A justificativa apresentada é convincente. É factível, realmente, pelo fato de ser tarde e de o cão não ter comido ainda, que ele de fato esteja com fome. Mas pode ser que não. Pode ser que ele esteja com algum problema digestivo, por exemplo, em face do qual não comeu e não quer comer, não estando com qualquer inclinação para fazê-lo. Isso conduz ao que Diego Marconi designa por "J3", que seria aquela justificação que, além de ser convincente, é verdadeira. Trata-se do terceiro e mais elevado grau de justificação possível para uma crença, ou para um enunciado que dela decorra.

A questão é que a precariedade do conhecimento humano - do acesso da mente humana à realidade a ser conhecida, seja ela natural, social ou ideal - torna impossível saber, ao certo, se uma afirmação é verdadeira e, portanto, se a justificativa apresentada é uma "J3". Por isso temos de nos conformar com uma justificativa "J2", mas deixar sempre em aberto a possibilidade de confrontá-la com evidências que a afastem (já que não saberemos jamais se ela é uma J3). Trata-se, aliás, de algo intrínseco à epistemologia contemporânea, dentro do que se convencionou chamar de falibilismo, ou falsificacionismo ${ }^{5}$. Todas as justificativas que nos são dadas, portanto, para fundamentar as mais variadas crenças, pretendem ser "J3", mas são no máximo "J2". Sempre está em aberto a possibilidade de serem afastadas e, nessa condição,

\footnotetext{
${ }^{5}$ POPPER, Karl. Em busca de um mundo melhor. Tradução de Milton Camargo Mota. São Paulo: Martins Fontes, 2006, p. 106-127; POPPER, Karl. A vida é aprendizagem - Epistemologia evolutiva e sociedade aberta. Tradução de Paula Taipas, São Paulo: Edições 70, 2001, p. 17.
} 
serem rebaixadas ao status de meras "J1", com outras justificativas passando a ocupar sua posição. Daí a essencialidade das refutações, e das críticas, que devem ser respondidas por quem pretender manter a justificação apresentada para as suas crenças como algo aceitável e convincente, vale dizer, como uma "J2" que almeja ser considerada, ainda que provisoriamente, como "J3".

\section{O "por que não?" como ponto de parada na cadeia infinita de fundamentos e a inafastabilidade do exame de possíveis objeções à crença fundamentada}

Para fundamentar uma crença, a qual é exteriorizada pelo sujeito que a possui por meio de afirmações (claims), utilizam-se outras afirmações. Desse modo, a busca por fundamentos para as crenças termina por conduzir a um regresso ao infinito, semelhante àquele em que se vê envolvido quem respeita e enfrenta a curiosidade de uma criança na "idade dos porquês".

Esse é um tema comum à literatura especializada em Epistemologia ${ }^{6}$. Geralmente se apontam três soluções em tese possíveis para ele: o regresso ao infinito, a interrupção dogmática ou a circularidade. Daí dizer-se que se trata de um trilema, em vez de um dilema, diante da existência de três caminhos para a solução do impasse. Karl Popper, contudo, talvez tenha oferecido uma boa solução para o trilema, melhor que as três usuais: a inversão do ônus argumentativo, decorrente da adoção da lógica falibilista ${ }^{7}$. Uma teoria jamais será considerada verdadeira, de forma definitiva. Será possível, contudo, demonstrar que ela é falsa. Assim, enquanto esse falseamento não ocorrer, ela será aceita como verdadeira, provisoriamente. Daí por que, para Popper, uma teoria será considerada científica quando puder, em tese, ser refutada, ou falseada. A solução para o trilema, então, é devolver a pergunta a quem nos pede seguidamente por fundamentos: "Por que não?"8

Trata-se de uma solução engenhosa, porque não é dogmática, não exige o regresso ao infinito, tampouco incorre em circularidade. Para-se na sequencia de fundamentações, por se chegar a um ponto em face do qual podemos nos dar por satisfeitos e agir (do contrário, o regresso ao infinito nos paralisaria). Mas, por outro lado, caso fundamentos adicionais sejam

\footnotetext{
${ }^{6}$ ATKINSON, David.; PEIJNENBURG, Jeanne. Fading Foundations. Probability and the regress problem. Cham: Springer, 2017, p. 4.

${ }^{7}$ POPPER, Karl. A lógica da pesquisa científica. 12.ed. Tradução de Leônidas Hengenberg e Octanny Silveira da Mota. São Paulo: Cultrix, 2006, p. 111-112.

${ }^{8}$ MARCONI, Diego. Per la verità. Relativismo e filosofia. Torino: Einaudi, 2007, p. 27.
} 
necessários - o que será evidenciado por eventual resposta à pergunta “por que não?” devolvida a quem cobra por fundamentos - pode-se prosseguir, sem dogmatismos ou circularidades.

Tais ponderações revelam, portanto, que enquanto subsistirem razões capazes em tese de infirmas nossas conclusões, não enfrentadas e afastadas, tais conclusões simplesmente não estarão fundamentadas, por mais que se apontem outros motivos que as sustentem. Não se trata de uma decorrência da legislação processual brasileira, mas uma constatação da própria Teoria do Conhecimento, aplicável às crenças em geral, gênero do qual as crenças do magistrado reduzidas a termo em uma sentença obviamente são uma espécie.

\section{O "modelo Toulmin" e a relevância do "rebuttal"}

O estudo do argumento contou, no Século XX, com a inestimável contribuição de Stephen Toulmin, que fornece modelo com a estrutura de um argumento, indicando os elementos em que se deve decompor, e que lhe emprestam justificação.

Quando se decide uma questão, faz-se com o uso de uma alegação (claim), que funciona como argumento ${ }^{9}$, por meio do qual se exprime a crença em determinado estado de coisas. Essa crença se fundamenta em uma inferência, feita a partir de dados prévios, e de uma garantia segundo a qual, de referidos dados, é possível chegar-se à conclusão pretendida. A garantia, por outras palavras, assegura ou confirma a existência de uma relação de causalidade entre os "dados" e as conclusões (a crença que se deseja fundamentar) dele extraídas. Mas a crença fundamenta-se, ainda, na ausência de possíveis exceções que, caso estivessem presentes, invalidariam a conclusão mesmo que os dados e a garantia fossem aceitos de maneira incontroversa. Os dados prévios fundamentam a conclusão, a garantia se presta a justificar a relação de causa e efeito entre ela e os dados prévios, justificação que se completa diante da ausência de exceções à referida conclusão ${ }^{10}$.

Exemplificando, se alguém afirma "João está triste", tem-se uma alegação (claim), a qual decorre da crença, de quem faz a afirmação, de que João está triste. Se alguém indagar "por quê??", diante dessa afirmação, estará à procura de fundamentos, sendo possível responder:

\footnotetext{
${ }^{9}$ Assim como as palavras conhecimento, interpretação, pensamento e raciocínio, a palavra "argumento" sofre da dubiedade processo-resultado, conforme já explicado. Nesta parte do texto, ela foi empregada como designando o resultado.

${ }^{10}$ Veja-se, a propósito: TOULMIN, Stephen. Os Usos do Argumento. São Paulo: Martins Fontes, 2001; PONTES, Fernando Demetrio de Sousa. Fundamentação das decisões judiciais e interpretação jurídica: estudo comparativo entre as contribuições da hermenêutica filosófica de Gadamer e do Modelo Toulmin de argumentação racional. Dissertação de Mestrado em Direito. Universidade Federal do Ceará. 2017. 120 f. Disponível em http://www.repositorio.ufc.br/bitstream/riufc/29579/1/2017_dis_fdspontes.pdf, acesso em 10 jun. 2019.
} 
"porque está chorando". Estar chorando aparece como o "dado" no qual se baseia a fundamentação. A ideia de que pessoas choram quando estão tristes fornece a garantia (warrant) de que, diante dos referidos dados, é legítima a conclusão de que João realmente está triste. Mas é possível que, mesmo corretos os dados e a garantia, exista alguma exceção que invalide a conclusão: "João está chorando de alegria" ou "João é ator e está ensaiando para representar cena em que seu personagem está triste", ou ainda "João estava cortando cebolas". Se tais exceções são afastadas, porque se constata que o choro não decorre de uma intensa alegria, nem da representação de uma cena como ator, ou dos efeitos de substâncias exaladas pela cebola cortada sobre seus olhos, é legítima a conclusão, a partir dos dados, e da garantia, de que João está triste.

Como se percebe, Toulmin decompõem as parcelas de um argumento, permitindo que se identifiquem as partes que o sustentam e cujas fragilidades podem amparar seu questionamento. É possível contestar os dados. Ou aceitar os dados, mas não a garantia. E é possível ainda acatar os dados, e a garantia, mas apresentar exceções que afastem a conclusão. E quem defende o argumento de cuja justificação se cogita não precisa demonstrar infinitamente aspectos desse argumento que não são questionados, resolvendo-se também assim a questão do regresso ao infinito inerente ao "trilema" subjacente à fundamentação do conhecimento, anteriormente mencionado.

Ao juiz, portanto, cabe, na sentença, não apenas deixar de incorrer nos óbvios vícios mencionados no art. 489, § 1. ${ }^{\circ}$, do CPC, mas: (i) indicar os dados dos quais extrai sua conclusão; (ii) explicar por que, de tais dados, é possível chegar à conclusão que chegou; (iii) afastar as possíveis exceções que, caso presentes, impediriam a sua conclusão mesmo que os elementos (i) e (ii) pudessem ser aceitos. E, se as partes indicarem motivos para que qualquer desses pontos não pudessem ser admitidos, caberá ao juiz explicar as razões pelas quais as alegações das partes, nesse particular, não podem ser aceitas. É o mínimo que se espera de uma sentença, a fim de que se garanta, minimamente, que o juiz está a aplicar a ordem jurídica, em respeito à separação de poderes, à legalidade e ao Estado de Direito, e não apenas suas convicções pessoais e preconceitos. A não ser assim, todo o Direito Material, e tudo o que se estuda, discute e publica a respeito dele, não farão o menor sentido no âmbito de um processo judicial. Também daí se conclui, sob um prisma filosófico, pelo caráter verdadeiramente essencial - para a aceitabilidade de um argumento (para que possa ser considerado pelo menos um "J2" - que enfrente as objeções que lhe são dirigidas. 


\section{O art. 489, § 1., IV, do CPC, é aplicável a qualquer decisão judicial ou administrativa}

Diante do que foi explicado nos itens anteriores, percebe-se que o art. $489, \S 1 .^{\circ}, \mathrm{IV}$, do CPC/2015 só enuncia o óbvio. Qualquer crença - e não só as que consubstanciam uma decisão judicial, quanto à ocorrência de fatos ou à interpretação de textos normativos - só está fundamentada de maneira aceitável (J2) quando rebate todas as objeções que lhe são dirigidas, e que sejam capazes de infirmá-la.

\subsection{Formalmente, o CPC é aplicável aos demais processos, nos quais não existam regras em contrário}

Nos termos do art. 15 do CPC/2015, na "ausência de normas que regulem processos eleitorais, trabalhistas ou administrativos, as disposições deste Código lhes serão aplicadas supletiva e subsidiariamente". Diante disso, mesmo uma mente mais formalista terá de admitir que o art. 489, $\S 1 .^{\circ}$, IV do CPC é aplicável a demais processos que não têm esse diploma como principal norma de regência.

Sabe-se, porém, que há vozes já a defender o contrário. No próprio processo civil, como se sabe, havia o entendimento de que o magistrado não precisaria responder todos os argumentos suscitados pelas partes, algo pacífico na jurisprudência do Superior Tribunal de Justiça. E, mesmo depois do CPC, há vozes a sustentar isso, por exemplo, no âmbito do processo trabalhista.

Não se trata, contudo, de uma imposição do meramente didático art. 489. Tampouco do art. 15 do mesmo Código. A imposição é epistemológica. E mais: é também jurídica, fruto de outras disposições da ordem jurídica, que complementam o dever constitucional de fundamentação de decisões. Os itens seguintes tratam de algumas delas.

\subsection{Processo administrativo e direito de petição}

No que tange aos processos administrativos, há razão adicional que impõe à autoridade a manifestação sobre todos os argumentos levantados pelas partes ${ }^{11}$. Trata-se do direito de petição, o qual envolve, evidentemente, o direito a uma resposta em face do que foi pedido.

\footnotetext{
${ }^{11}$ Com exceção, conforme explicado, apenas daqueles que restam prejudicados pelos fundamentos já indicados, o que aliás explica a expressão "capazes de infirmar a conclusão adotada pelo julgador" constante do art. $489, \S$ 1. ${ }^{\circ}, \mathrm{IV}$, do CPC.
} 
Seria, com efeito, risível se se assegurasse ao cidadão o direito de "pedir" o que quer que fosse à autoridade, e essa não fosse obrigada a responder, podendo passar no triturador ou arrastar para a lixeira, em um ambiente virtual - o pedido formulado, sem responde-lo. Corresponderia esse direito, nesse caso, à faculdade de perder tempo, ou de ser feito de tolo. É óbvio que o direito de pedir envolve o direito a uma resposta, a qual até pode não acatar o que foi pedido, indeferindo o pleito do requerente, mas que deve necessariamente respondê-lo, declinando as razões pelas quais não é acolhido.

No processo administrativo, portanto, o disposto no art. $489, \S 1 .^{\circ}$, IV do CPC reflete não só uma obviedade epistemológica, mas uma consequência do próprio direito de petição, impondo seu respeito independentemente do que dispõe o art. 15 do CPC e, do mesmo modo, ainda que eventual disposição de lei específica sinalize em sentido contrário (contrariedade que, portanto, será simplesmente inconstitucional).

\subsection{Devido processo legal, ampla defesa e contraditório e o direito de ter os argumentos enfrentados}

A mesma lógica referida relativamente aos processos administrativo, e ao direito de petição, aplica-se por igual a todo e qualquer outro processo que vise a resolver um conflito, no âmbito do qual as partes tenham direito à ampla defesa e ao contraditório, desdobramentos da ideia de devido processo legal substancial. Seria nula, inexistente, meramente ornamental, a faculdade de defender-se, carrear meios de provas aos autos, aduzir argumentos, se o julgador não fosse obrigado a se manifestar sobre eles, pelo menos para dizer por que não os acolhe.

E isso vale não apenas para as teses jurídicas que eventualmente sejam opostas àquela acolhida pelo julgador, na interpretação e na aplicação de textos normativos, mas também - e principalmente - no enfrentamento de questões de fato. ${ }^{12}$ Exemplificando, se nos autos de um processo que versa matéria tributária alguns meios de prova geram a presunção de que um contribuinte omitiu rendimentos, enquanto outros geram a presunção de que ele não omitiu, o magistrado deve examiná-los todos, dando especial atenção àqueles que conduzem a conclusão contrária àquela por ele acolhida na sentença. Se considera que houve omissão de rendimentos, mas o perito afirmou que não houve, o magistrado deve apontar as razões pelas quais considera que o laudo está equivocado. Evidentemente, não será uma "fundamentação", nesse caso, a

\footnotetext{
12 TARUFFO, Michele. La semplice verità. Il giudice e la costruzione dei fatti. Roma: Laterza, 2009, p. 243.
} 
mera referência art. 436 do CPC $^{13}$ e aos meios de prova (v.g., cópia do auto de infração, o qual teria "presunção de validade") que conduzem a conclusão diferente, dizendo que "prefere" esses outros. É preciso dizer por que o laudo é tido por equivocado, ou, por outros termos, por que se deu preferência aos outros meios de prova que apontam em sentido contrário. Quanto ao laudo pericial, aliás, o art. 479 é explícito ao determinar que o juiz indique na sentença "os motivos que o levaram a considerar ou a deixar de considerar as conclusões do laudo, levando em conta o método utilizado pelo perito."

Tudo isso mostra que tais princípios, construídos em um lento processo de tentativa e erro que os seres humanos aplicam às instituições que criam, convergem com a ideia epistemológica de fundamentação das crenças, dando força à obviedade enunciada no art. 489, $\S 1 .^{\circ}, I V$, do CPC. Trata-se de uma obviedade necessária, porquanto Tribunais não agiam assim antes do Código, e alguns insistem em continuar não agindo mesmo depois dele, partindo de disparatados argumentos formalistas ligados a uma alegada "inaplicabilidade" do CPC aos processos que perante eles tramitam. É o caso, por exemplo, da invocação de que o art. 489 do CPC não seria aplicável ao processo do trabalho diante do art. 852-I da CLT, cuja redação é a seguinte: “A sentença mencionará os elementos de convicção do juízo, com resumo dos fatos relevantes ocorridos em audiência, dispensado o relatório."

Além de tal disposição não ser superior ao dever constitucional de fundamentação das decisões, e a tudo que dele decorre, é óbvio que não é possível interpretá-la literal e isoladamente, como se o juiz pudesse invocar qualquer coisa (uma "J1") para fundamentar sua decisão. Não há "pressa", quantidade de processos ou "maior informalidade" que justifiquem tamanho despropósito.

Reconheça-se, quanto a isso, que o dever constitucional de fundamentar decisões, constante da norma veiculada pelo art. 93, IX, da CF/88, e cujo conteúdo é parcialmente explicitado, a contrario, pelo art. 489 do CPC, realmente decorre de um princípio nos termos propostos por Robert $\mathrm{Alexy}^{14}$, a saber, um mandamento de otimização, a ser realizado na medida em que isso for factual e juridicamente possível. Como consequência, o dever de fundamentar a decisão não poderia levar o magistrado a proferir sentença com infinitas páginas,

\footnotetext{
13 “Art. 436. O juiz não está adstrito ao laudo pericial, podendo formar a sua convicção com outros elementos ou fatos provados nos autos."

${ }^{14}$ A propósito, veja-se GUERRA, Marcelo Lima . Notas sobre o dever constitucional de fundamentar as decisões judiciais (CF, art. 93, IX). In: Luiz Fux; Nelson Nery Junior; Teresa Arruda Alvim Wambier. (Org.). Processo e Constituição: estudos em homenagem ao Professor José Carlos Barbosa Moreira. São Paulo: Revista dos Tribunais, 2006, p. 517-541.
} 
até porque isso implicaria malferimento a outras normas constitucionais, como as que impõem ao Estado a prestação da tutela jurisdicional, que há de ser célere, permitir a imposição de recursos etc. A fundamentação, nessa ordem de ideias, deve ser a mais completa e detalhada possível, sendo limitações a essa possibilidade não a paciência do juiz ou sua disposição no momento, mas a própria necessidade de o processo seguir adiante. Considera-se suficiente a fundamentação, e atendido o dever de indicá-la, quando a partir dela for possível racionalmente aceitar a decisão, e inverter o ônus argumentativo para quem quiser se opor a ela, que deverá indicar os motivos pelos quais ela é equivocada. Trata-se precisamente do que explicita o art. $489, \S 11^{\circ}$, do CPC, em especial seu inciso IV, ora em exame. Desse modo, a prevalecer a compreensão de que em processos dotados de "maior informalidade" seria lícito afastar o aludido dispositivo, admitir-se-ia que neles o magistrado (v.g., trabalhista) fizesse constar da sentença que decide de determinada maneira porque "sim!", ou "era o certo", "lhe deu na telha", "viu duendes que lhe sugeriram essa solução", "empresários são todos safados", "não foi com a cara da parte" ou "porque seu horóscopo sugeriu assim", pois em todas essas hipóteses estaria, literal e sinceramente, mencionando os (ainda que amalucados) "elementos de convicção do juízo". O absurdo dispensa comentários adicionais.

\section{Considerações finais}

Diante do que foi exposto, conclui-se que o enfrentamento de argumentos - de fato e de direito - capazes de infirmar as conclusões a que chega o julgador, na prolação de uma sentença, não é decorrência (apenas) do que didaticamente explicita o art. 489, § 1. ${ }^{\circ}, \mathrm{IV}$, do CPC. A imposição é mesmo epistemológica, não sendo possível afirmar que uma crença - seja ela de um cientista, de um pesquisador, ou de um juiz - está fundamentada se as objeções que lhe são dirigidas não forem enfrentadas. Não basta indicar os "porquês" da convicção, sendo imperioso afastar, sobretudo, o que fora alegado pelas partes diante de um possível "por que não?”. Essa é a razão pela qual a obviedade enunciada pelo $\mathrm{CPC}$, conquanto redundante, didática, e meramente explicitante de algo que deveria ser seguido independentemente do que se acha escrito na lei, é aplicável a todos os processos, aliás a todas as crenças - filosóficas, científicas, judiciais ou administrativas - para as quais seja lícito cobrar fundamentos, independentemente do que conste em subsistemas infraconstitucionais processuais mais específicos, a exemplo do administrativo, do trabalhista, ou de qualquer outro. 


\section{REFERÊNCIAS}

ATKINSON, David.; PEIJNENBURG, Jeanne. Fading Foundations. Probability and the regress problem. Cham: Springer, 2017.

FUX, Luiz; NERY JUNIOR, Nelson; WAMBIER, Teresa Arruda Alvim. (Org.). Processo e Constituição: estudos em homenagem ao Professor José Carlos Barbosa Moreira. São Paulo: Revista dos Tribunais, 2006.

GUERRA, Marcelo Lima. Notas sobre o dever constitucional de fundamentar as decisões judiciais (CF, art. 93, IX). In: FUX, Luiz; NERY JUNIOR, Nelson; WAMBIER, Teresa Arruda Alvim. (Org.). Processo e Constituição: estudos em homenagem ao Professor José Carlos Barbosa Moreira. São Paulo: Revista dos Tribunais, 2006.

MARCONI, Diego. Per la verità. Relativismo e filosofia. Torino: Einaudi, 2007.

PONTES, Fernando Demetrio de Sousa. Fundamentação das decisões judiciais e interpretação jurídica: estudo comparativo entre as contribuições da hermenêutica filosófica de Gadamer e do Modelo Toulmin de argumentação racional. Dissertação de Mestrado em Direito. Universidade Federal do Ceará. 2017. 120 f. Disponível em http://www.repositorio.ufc.br/bitstream/riufc/29579/1/2017_dis_fdspontes.pdf, acesso em 10 jun. 2019.

POPPER, Karl. A lógica da pesquisa científica. 12.ed. Tradução de Leônidas Hengenberg e Octanny Silveira da Mota. São Paulo: Cultrix, 2006.

POPPER, Karl. A vida é aprendizagem - Epistemologia evolutiva e sociedade aberta. Tradução de Paula Taipas, São Paulo: Edições 70, 2001.

POPPER, Karl. Em busca de um mundo melhor. Tradução de Milton Camargo Mota. São Paulo: Martins Fontes, 2006.

TARUFFO, Michele. La semplice verità. Il giudice e la costruzione dei fatti. Roma: Laterza, 2009.

TOULMIN, Stephen. Os Usos do Argumento. São Paulo: Martins Fontes, 2001. 